\title{
Launch failure dents India's space plans
}

New Delhi. India's ambitious plans to enter the satellite launch business by 1995 received a major setback last week when its most powerful rocket failed in its maiden flight from the Sriharikota launch pad on the east coast, plunging into the Bay of Bengal shortly after take-off with its $850-\mathrm{kg}$ cargo.

A preliminary report by a committee set up to analyse the failure says that the polar satellite launch vehicle (PSLV) seems to have been operating normally. It blamed the disaster on an "unexpected disturbance" during the separation of its second stage.

Whatever the cause, the failure is a blow to the Indian Space Research Organization (ISRO), already facing difficulties created by the imposition of technology embargoes

\section{Academies urge population control}

London. The science academies of most of the world's leading industrialized and developing nations - including the United States, Russia, China and India - are planning to issue a joint statement next month on the need for governments to do more to control the growth of their populations.

The final text of the statement is due to be agreed at a five-day meeting in New Delhi, India. It is expected to state that population control is essential for any country wanting to raise its standard of living while preserving its environment, and to endorse a variety of measures, including in particular the promotion of both sex education and birth control techniques, to achieve this goal.

This is the first time that such a joint action has been taken, and the statement will be primarily addressed to the 1994 United National Conference on Population and Development. One proposal to be discussed in New Delhi is the creation of a standing committee to provide scientific advice to participants at the conference, similar to that established for last year's Earth Summit in Rio de Janeiro by the Intergovernment Panel on Climate Change.

But the organizers of the meeting, described as a "science summit", also say that they hope the joint statement will be used by academies of science at a local level, particularly in the developing countries, to persuade governments to increase their efforts to reduce the growth of population.

The joint statement follows two separate initiatives, one a similar statement issued last year by the US National Academy of Sciences and Britain's Royal Society, and the other a meeting on population organized by the Royal Swedish Academy of Sciences. Both in turn were stimulated by a belief that the Rio meeting neglected population problems in addressing environmental issues.

"The meeting did nothing about the prob- by the United States, and Russia's decision to back out of a contract to supply cryogenic technology needed for ISRO's geostationary satellite launch vehicle (GSLV).

A successful PSLV launch would have boosted the morale of the staff of both the ISRO and 150 companies who have been working on the PSLV project since 1983. U. R. Rao, the head of ISRO, says that the next PSLV will be ready for testing in 12 months, and that the launch vehicle will become available for commercial launch after three successful flights.

According to Rao, the PSLV flight was not a total failure because it demonstrated the effectiveness of two technologies being used by ISRO for the first time: a liquid lem of population growth, despite all the talk about carbon dioxide and global warming", says Sir Francis Graham-Smith, physical secretary of the Royal Society. "We now have a worldwide network of science academies saying something needs to be done."

Replying to the charge that the meeting was neglecting the many social and economic pressures which also lead to the destruction of the environment, Graham-Smith said that the academies were focusing on the population issue "because that is the one side of this complex question which has been dodged in the past".

Among those attending the meeting will be delegates from the Vatican Academy of Sciences. But the academy is not expected to sign the final declaration. Graham-Smith acknowledges that the Vatican's opposition to birth control - expected to be repeated in a new encyclical shortly to be issued by the Pope - "would make it difficult for them to subscribe to any statement which comes out of the meeting."

David Dickson engine for main propulsion, and the world's third largest 128-tonne solid motor. As these pieces of equipment are also used in GSLV, ISRO feels reassured about its design.

With only three successful launches (out of seven) to its credit in 13 years, ISRO took a calculated risk in putting its new model on the launch pad before its two earlier models - the SLV-3, which can lift the equivalent of two suitcases, and the ASLV, which can carry $100 \mathrm{~kg}$ - are fully operational.

Observers say that ISRO was in a hurry to introduce the PSLV in order to gain quick access to the international launch market, which is already getting crowded with the entry of China, Japan and Russia.

Designed to place 1-tonne satellites in low Earth orbit, the 275-tonne PSLV is ideal for launching remote sensing and scientific satellites, says ISRO. The space organization spent \$140 million on the PSLV project over the past 12 years. But it says it can produce individual launchers at $\$ 15$ million each, offering a launch service at half the cost of those of Western countries.

India, a recent entry in the space business, formed a company called Antrix corporation last year. It has so far secured orders worth US\$300,000 from INMARSAT, a London-based satellite maritime communications organization. And ISRO is bidding for the contract to launch some of the 66 satellites that will make up Motorola's project for global communication with hand-held terminals, known as Irridium.

Antrix has already received several enquiries about Indian-built satellites. "This is because we make them cheaper", says Rao, who said Antrix can supply a geostationary communication satellite for $\$ 24$ million against $\$ 100$ million for a similar product from Western countries. "With four of our satellites now working beautifully in space, ISRO's credibility in satellite technology has gone up."

K.S. Jayaraman

London. Sir Mark Richmond (right) is to step down at the end of the year as full-time chairman of Britain's Science and Engineering Research Council to become director of the UK research division of the pharmaceutical company Glaxo. He will also co-ordinate the company's international research.

Announcing his decision last week, Sir Mark said that he had decided not to put his name forward as a candidate for the new post of Director-General of Research Councils, a position whose creation was announced in the recent white paper (policy document) on the organization of science.

He will, however, remain as part-time chairman of the SERC up to April 11994. This is the date on which the council is due to be split into various parts, the biggestbeingtheEngineeringand Physical Sciences Research Council and the Particle Physics and Astronomy Research Council. take over from RichardSykes - recently appointed chief executive - as head of the biggest private sector research and development programme in Britain. As such, Sir Mark is likely to continue to play a central role in science policy debates at government level.
At Glaxo, he will 